\title{
ATLANTIS: techno-economic model of the European electricity sector
}

\author{
Heinz Stigler $^{1}$ • Udo Bachhiesl ${ }^{1}$ - Gernot Nischler ${ }^{1}$. \\ Gerald Feichtinger ${ }^{1}$
}

(C) The Author(s) 2015. This article is published with open access at Springerlink.com

\begin{abstract}
Since the nuclear accident in Fukushima the European electricity economy has been in transition. The ongoing shut down of nuclear power plants and the widespread installation of wind power and photovoltaic generation capacities, especially in Germany, has led to a high share of intermittent renewable electricity production. This high amount of generation with very little variable cost has led to a significant decline of the prices at the European energy exchange. This has meant that many thermal power plants are no longer able to work economically and have already been shut down, although they would be needed in times of high demands and as backup capacities. Therefore, a redesign of the European electricity market is needed and in order to find out the right characteristics and effects of such a redesign pre-investigations based on simulation models are reasonable. This paper introduces ATLANTIS, which is a simulation model of the European electricity economy and covers technical as well as economic and environmental issues and allows the calculation of different scenarios up to 2050 and even beyond regarding the specific characteristics of the electricity economy. After a comprehensive introduction of the model some example applications and an outlook are presented.
\end{abstract}

\footnotetext{
$\triangle$ Udo Bachhiesl

Bachhiesl@TUGraz.at

http://www.IEE.TUGraz.at

Heinz Stigler

Stigler@TUGraz.at

Gernot Nischler

gernotnischler@yahoo.de

Gerald Feichtinger

Gerald.Feichtinger@TUGraz.at

1 Institute of Electricity Economics and Energy Innovation (IEE), Graz University of Technology (TU Graz), Graz, Austria
} 
Keywords Electricity economics - ATLANTIS - Simulation model · Electricity network development planning $\cdot$ DC-OPF $\cdot$ Capacity mechanisms $\cdot$ Shadow prices

\section{Introduction}

The European Union is very dependent on energy imports and therefore established its own energy strategy and defined the well-known 20-20-20 targets. ${ }^{1}$ The nuclear disaster in Fukushima has above all led to a rethinking, especially in the European electricity economy. Among other countries, Germany as a leading country has decided to shut down all nuclear power plants by the year 2022 and to increase electricity production from renewable energy sources (RES). This process is called "Energiewende" and has led to a shift in the electricity system. Due to the installation of more than $38.5 \mathrm{GW}$ of photovoltaics (PV) (cf. Wirth 2015) and $38.1 \mathrm{GW}$ of wind power (cf. BWE 2014) the whole electricity system has become more decentralised and the production more volatile. On the one hand this trend determines the further development of the electricity grid and on the other hand it also influences the electricity market. Up to now the electricity market has been organised as an energy-only-market, which means that the market clearing price is formed by the variable production costs of the power plants. Due to the widespread installation of RES production capacity with very little variable costs the electricity price at the European Energy Exchange has decreased significantly in the recent years. This situation often made it economically inefficient to run thermal power plants and therefore many of those power plants have already been shut down or the operation will be stopped soon, ${ }^{2}$ although this capacity is needed in times of high demand or as a backup when the RES production is not present.

This short introduction shows that a lot of questions regarding the development of the future electricity system have to be adressed and those questions are not only of a technical but also of an economic nature. In order to find out the right way for the future development of the European electricity system, scenario investigations are helpful, but the used models have to cover a corresponding time frame as well as the particularities of the electricity economy.

This paper presents a simulation model for the European electricity economy called ATLANTIS. The model has been developed at the Institute of Electricity Economics and Energy Innovation (IEE) of Graz University of Technology during the last 12 years. Every part of the model is self-developed and the used data is unrestricted and can be used independently. ATLANTIS allows long-term scenario calculations (up to the year 2050 and even beyond) and also includes the technical as well as the economic sphere of the electricity system. One particularity of the model is that the huge complexity of the electricity system is covered. It includes on the technical side the demand (at the level of every single net node), transmission network (including DC load flow calculations and HVDC lines), power plants (including thermal, nuclear and renewable) as well as the electricity companies (including balances and income statements) and the

\footnotetext{
1 A $20 \%$ reduction in EU greenhouse gas emissions from 1990 levels; Raising the share of EU energy consumption produced from RES to $20 \%$; A $20 \%$ improvement in the EU's energy efficiency.

2 According to the list of power plant closure notifications (cf. Bundesnetzagentur 2015) of the German regulator $8071 \mathrm{MW}$ of thermal power plants are listed for shut-down
} 
electricity market (including electricity exchange) on the economic side (cf. Stigler and Bachhiesl 2015). In the recent years a comprehensive visualisation tool (VISU) has been developed and added to ATLANTIS. The visualisation of the huge amount of generated data plays an important role in order to support the scenario generation and the interpretation of the gained results. The development of ATLANTIS has been nearly stopped twice because of the complexity of the modelling approach. If possible therefore some simplifications have been done without significantly influencing the results. For example the model uses a DC instead of an AC load flow calculation and also works with discretised duration curves instead of performing 8760 calculations per year. Those assumptions are valid, because the model is designed for long-term system development investigations and therefore the input data for such long periods are uncertain. In general ATLANTIS allows to do "iterative optimizations". This is necessary since in reality there exist more than one target function which are very complex and often divergent. Our energy economy should be affordable, secure, sufficient and environmental friendly and those targets are in close relation to the economic political targets like economic growth, full employment, equity, monetary stability and external trade balance (cf. Stigler 2002). Through the interdisciplinary modeling approach ATLANTIS is a successful instrument that aids understanding complex problems in the European electricity economy and helps to support decision-making processes.

The paper is organized as follows. After the introduction in Sect. 1, an overview of existing modelling approaches is given in the literature review in Sect. 2. Section 3 describes the simulation model ATLANTIS and Sect. 4 shows examples of already done applications of ATLANTIS. In Sect. 5 conclusions are drawn and an outlook is given.

\section{Literature review}

The electricity sector is a major part of the whole energy system which is subject matter for energy planning approaches (cf. Thery and Zarate 2009; Kakogiannis et al. 2014). This chapter shows some of the present electricity modelling approaches with the main application focus on the European electricity sector.

The PRIMES model is a detailed agent-based and price-driven model of the energy system which covers 35 European countries. PRIMES consists of several sub-models for different demand sectors and energy supply systems, including a detailed electricity model. PRIMES is used by different departments of the European Commission and individual member states for the evaluation of various energy system adjustments (cf. Capros 2000).

The French transmission system operator $\mathrm{RTE}^{3}$ developed a new tool for adequacy reporting of electric systems in order to give transmission system operators (TSO) additional joint analysis capabilities. The model is called ANTARES and is specifically designed to carry out multi-area adequacy studies. The model comprises 500 nodes for the whole of Europe and simulates in 1-h steps. ANTARES has been used by a

\footnotetext{
${ }^{3}$ Réseau de Transport d'Electricité.
} 
number of ENTSO-E ${ }^{4}$ regional groups and various results have been included in the Ten-Year Network Development Plan (TYNDP) (cf. Doquet et al. 2008, 2011).

The Institute of Energy Economics at the University of Cologne developed the electricity models MORE and DIMENSION. Market Optimization of Electricity with Redispatch in Europe (MORE) is based on mixed-integer-programming and it calculates the total cost of the electricity system as well as the optimal dispatch. The model allows the calculation of a large number of different scenarios and covers geographically all connected European markets and North Africa. DIMENSION is a long-term simulation model which covers the EU-27 countries. The model is based on a comprehensive database containing all power plants and storage facilities, which allows the simulation of the development of the European generation park. Additionally various models have been developed, which can be patched in the basic model (cf. EWI Cologne 2014).

The TIMES ${ }^{5}$ model generator was developed by an international community as part of the IEA-ETSAP. ${ }^{6}$ It is based on long-term energy scenarios to conduct indepth energy and environmental analyses. The TIMES model generator consists of a technical as well as an economic part. It is a bottom-up model generator which uses linear-programming to produce a least-cost energy system considering a number of user constraints. This model is applied by a broad variety of different users from science and public authorities (cf. Loulou et al. 2005; Remme 2006).

PowerACE is an agent-based simulation model which covers the different market participants including end customers, electricity providers, producers of electricity from RES, TSO and market operators. The model focuses on the German electricity market and allows the investigation of e.g. merit order effects, questions regarding market power or impacts of emission trading (cf. Genoese et al. 2007, 2008).

The PERSEUS model (Programme Package for Emission Reduction Strategies in Energy Use and Supply) is a multi periodic energy and material flow model of the European electricity supply system with a modelling time horizon from the year 2007 to 2050 . A simulated year is represented by a typical week and weekend day for the seasons, resulting in 44 time intervals for 1 year. The model is based on linear and mixed-integer programming approaches and the target function consists of a minimisation of all decision-relevant expenditures within the entire system (cf. Möst 2006; Fichtner 1999).

The ELMOD model consists of a bottom-up approach with welfare maximisation as the objective function and minimisation of total system costs and also includes the physical characteristics of load flow, energy balance and generation restrictions (cf. Leuthold et al. 2010).

Some model approaches adress directly the functioning and future design of the electricity market (cf. Kocan 2008; Vasin et al. 2013) in order to reduce the risks for the needed further power plant investments (cf. Vespucci et al. 2014; Regos 2013).

\footnotetext{
4 European Network of Transmission System Operators for Electricity.

5 The Integrated MARKAL-EFOM System.

6 International Energy Agency Energy Technology Systems Analysis Program.
} 


\section{Structure and functioning of the ATLANTIS scenario model}

The electricity economy is a very complex system characterised by paradigms like non-storable production, network bondage, yield-dependent versus demand-oriented generation characteristics or very high capital intensity. The aim of ATLANTIS is to handle this complexity within one single simulation model to give answers about e.g. the future development of electricity prices, future investment needs in generation and network assets, the system integration of RES, the economic benefits of new transmission lines and the effects of new market designs.

Compared to other electricity economical models ATLANTIS introduces some innovations. First of all this model covers the real and nominal economical parts of the European electricity system. Moreover it combines the calculation of energy balances including the power plant dispatch with a detailled loadflow model. Those applications are combined with an electricity market model for the simulation of competition. Compared to other model approaches ATLANTIS combines the mentioned parts for the European electricity system in one single model in high quality.

The structure of ATLANTIS, illustrated in Fig. 1, can be divided into the database and the model core.

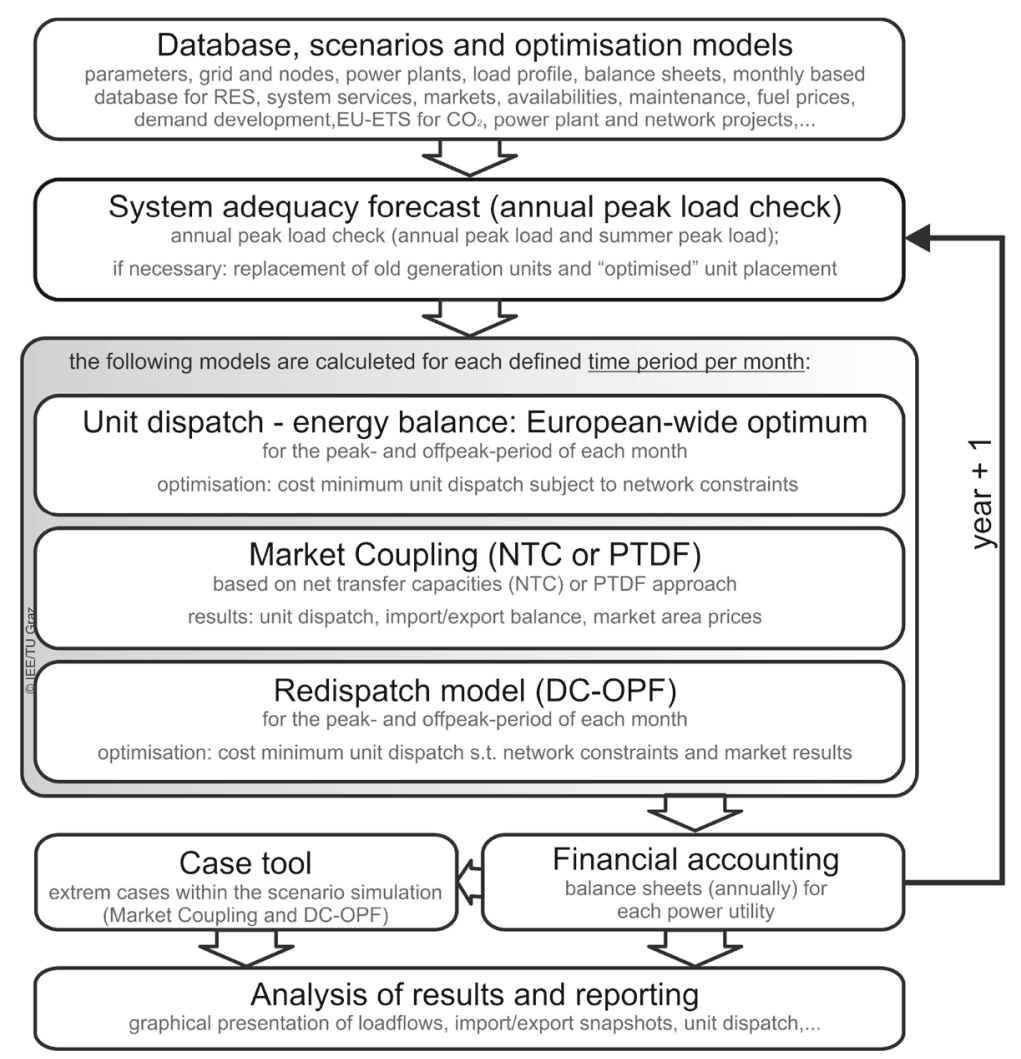

Fig. 1 Flow chart of the ATLANTIS scenario model 


\subsection{Database of the ATLANTIS scenario model}

The database is subdivided into existing assets (power plants, grid elements etc.) and planned assets (scenario data). The current database in ATLANTIS contains:

- 29 countries of the ENTSO-E CE regional group "Continental Europe";

- more than 19,400 power plants (including 7500 planned generation units and aggregated RES power plants). Each power plant is described by up to 44 different entries (e.g. nominal capacity, commissioning date, fuel type etc.) (cf. Fig. 2);

- 30 unit types with defined efficiency factors, overnight investment costs, parameters for learning curves, specific $\mathrm{CO}_{2}$ emission factors, availability and maintenance time, etc.;

- up to 15 fuel types for each country, with the possibility to define an individual price development curve for each fuel;

- about 4000 nodes (buses) of the European transmission network (380, 220 and $110 \mathrm{kV}$ if necessary) where each node is composed of up to ten different specifications (e.g. voltage level, consumption);

- more than 6300 existing network elements, like transmission lines inclusive high-voltage-direct-current (HVDC) links, autotransformers and phase shifting transformers in the $380 / 220 \mathrm{kV}$ network (including $110-150 \mathrm{kV}$ lines which are important for load flow analysis) where each grid element is composed of 22 specifications (e.g. voltage level, maximum current, reactance) (cf. Fig. 2);

- around 1300 planned grid enhancement projects (incl. HVDC projects), modelled according to the national and international network development plans and grid studies;

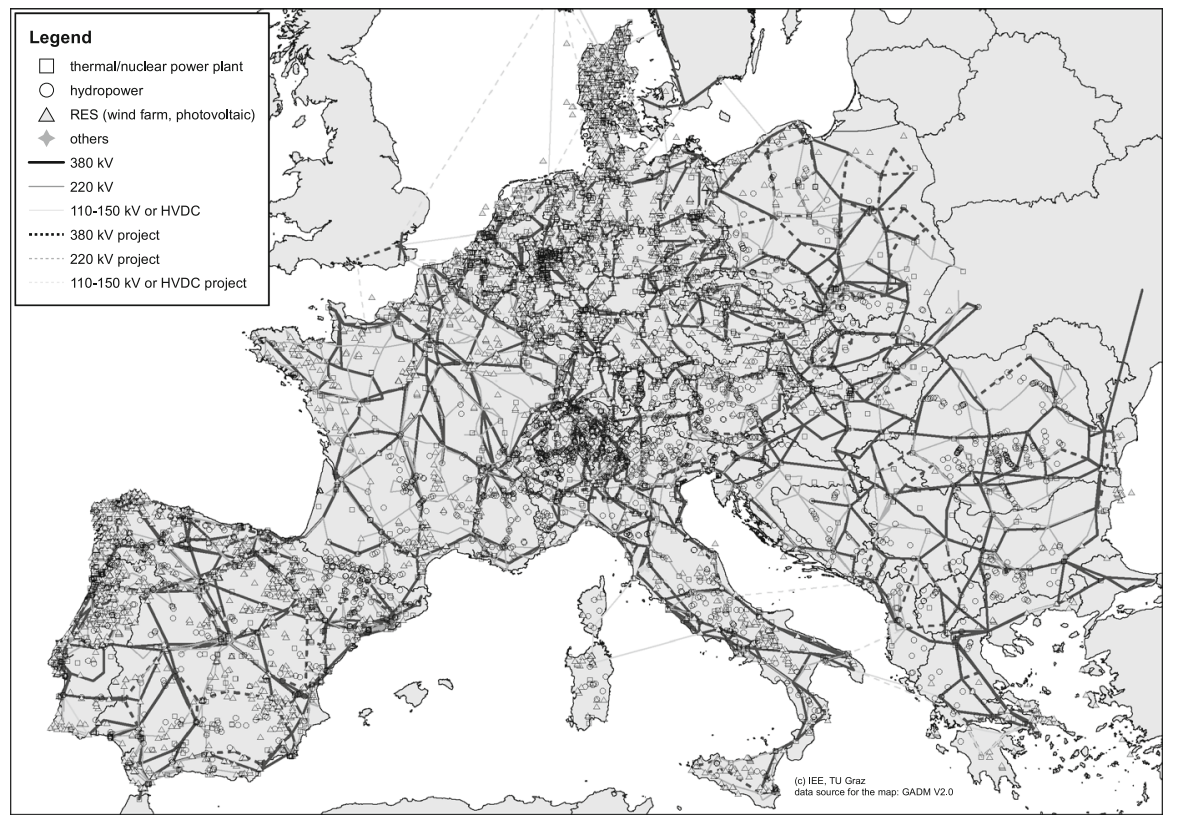

Fig. 2 Transmission grid and generation infrastructure in the ATLANTIS database (2012) 
- about 100 electric power and supply utilities with simplified balance sheets and income statements for the base year 2006.

The simulation of the future development of the European electricity economies is based on the database and also on the defined scenarios. These scenarios include the future development of fuel prices, the development of consumption and economic growth, net expansion projects and, last but not least, future decisions in energy policy.

\subsection{Model core and workflow of ATLANTIS}

As shown in Fig. 1 the model core of ATLANTIS includes different modules like the calculation for covering the annual peak load or the market coupling models. Due to this modular concept ATLANTIS can be adapted in order to investigate different electricity-economic research questions.

\subsubsection{Annual peak load calculation}

According to the predefined scenario assumptions the calculations are performed on an annual or monthly base. The calculation starts with a check as to whether the yearly peak load can be covered by the existing generation capacities considering the restrictions of the transmission grid. In ATLANTIS the load flow in the transmission grid is calculated by means of a direct current (DC) load flow algorithm. Bottlenecks will be identified and new power plants will be built at appropriate locations based on an algorithm which identifies the relevant grid nodes at which a minimum of additional feed-in power can cover the demand and thereby solve the grid congestions. The annual peak load check is performed for the winter peak load, which is significant for most countries, and the summer peak load, which is important especially in the southern countries like Spain, Italy and Greece. The annual peak load test determines the power and location of new required generation capacities.

\subsubsection{Monthly based unit dispatch: market coupling and DC-OPF}

In the next step the dispatch of power plants in order to cover the demand in the peak and off-peak period is calculated on a monthly basis. Each month can be divided into different peak and off-peak periods. A subdivision into two peak and two off-peak periods turns out to be an optimal choice between accuracy compared with the reality (e.g. import/export balances, zonal prices) and acceptable model calculation times. The first module in this monthly based model loop follows the idea of a Europe-wide optimal unit dispatch and regards the load flow equations in a second step. This power plant dispatch is performed according to market principles and orientated on minimum variable costs of generation. Furthermore, a power exchange in which the modelled companies trade generation surpluses, is calculated parallel to the dispatch.

The next model component is the European market coupling model. Many different parameters like the maximum and minimum power of conventional generation units, availability and maintenance factors on monthly basis, efficiency factors depending on the age of the power unit etc. are considered in the merit order of unit marginal 
costs. The fluctuating generation characteristic of run-of-river hydro power plants, $\mathrm{PV}$ or wind power plants is considered by the long-term average generation in the particular month and for each NUTS $-2^{7}$ area in Europe (cf. Schüppel 2010; Mayer 2010; Maier 2010). Also the must-run character of combined heat and power generation units (CHP) is modelled by using monthly-based heating degree days within a NUTS-2 geographical resolution. Depending on the research task two different model approaches for market coupling can be applied.

NTC-based market coupling The first approach is based on the concept of the Net Transfer Capacities (NTC). This NTC-based implicit market coupling (cf. Nischler 2009 ) is the mostly used concept for market-based cross-border congestion management since the beginning of the liberalisation of the European energy market. The model [cf. Eq. (1)] is defined as a linear optimisation problem with the objective to maximise the social welfare (by minimising the entire generation costs).

$$
\begin{aligned}
\max _{q D, q S} & \left\{\sum_{i}\left[\sum_{n}\left(q D_{n, i} \cdot p D_{n, i}\right)-\sum_{a}\left(q S_{a, i} \cdot c_{v a r} S_{a, i}\right)\right]\right\} \\
\text { s.t. } & q S_{a, i} \leq q S_{\text {max }_{a, i}} \\
& q D_{n, i} \leq q D_{\text {max }_{n, i}} \\
& \text { export }_{i \rightarrow j}-\text { import }_{i \rightarrow j} \leq N T C_{i \rightarrow j} \quad \forall(i, j \mid i \neq j) \\
& \sum_{k} \text { export }_{k \rightarrow j}-\sum_{k} \text { import }_{k \rightarrow j} \leq T P_{k \rightarrow j} \quad(k \subset i \wedge j \notin k) \\
& \sum_{a} q S_{a, i}-\sum_{n} q D_{n, i}+\sum_{i \neq j} \text { import }_{i \rightarrow j}-\sum_{i \neq j} \text { export }_{i \rightarrow j}=0 \quad \forall i
\end{aligned}
$$

with:

$i, j: \quad$ bidding zones, market areas

$k$ : defined technical profiles between market areas

$n$ : $\quad$ block bid of demand

$a$ : $\quad$ block bid of supply

$q D_{n, i}: \quad$ cleared part of demand block $\mathrm{n}$ in market $\mathrm{i}(\mathrm{MW})$

$q S_{a, i}: \quad \quad$ cleared part of supply block a in market i (MW)

$p D_{n, i}: \quad$ demand price (€/MWh)

$c_{\text {var }} S_{a, i}: \quad$ marginal costs of supply block a in zone i (€/MWh)

import $_{i \rightarrow j}: \quad$ import in market i from market $\mathrm{j}(\mathrm{MW})$

export $_{i \rightarrow j}$ : $\quad$ export from market $\mathrm{i}$ to market $\mathrm{j}(\mathrm{MW})$

$N T C_{i \rightarrow j}: \quad$ net transfer capacity between market $\mathrm{i}$ and $\mathrm{j}$ (MW)

$T P_{k \rightarrow j}: \quad$ technical profile between marketset $\mathrm{k}$ and $\mathrm{j}(\mathrm{MW})$

There exist some crucial disadvantages for the NTC-based market coupling approach in highly-meshed networks like the continental European transmission grid. Some of them are outlined, for example, in Louyrette and Trotignon (2009), Kurzidem

${ }^{7}$ Nomenclature des units territoriales statistiques. 
(2010) and Stigler and Bachhiesl (2014). One of the most critical drawbacks of the NTC concept is the disregard of the network bondage attended by the bilateral capacity calculation approach (cf. ETSO 2001). This leads to high transmission reliability margins (TRM) and in consequence to obstacles for the integrated electricity market in Europe. For this reason there are ongoing developments for load-flow-based market coupling in Europe (e.g. cf. CASCEU 2013). Moreover load-flow-based market coupling is ranked as the first-best solution in the European target model (cf. ENTSOE 2012) for the future capacity calculation and allocation mechanism. In answer to this development load-flow-based market coupling is the second approach that can be applied in the simulations with ATLANTIS.

Loadflow-based market coupling Equal to the NTC-based market coupling algorithm the objective function of the optimisation problem for load-flow-based market coupling [cf. Eq. (2)] is defined as a maximisation function for the social welfare (by minimising the overall generation costs) (cf. Nischler 2014).

$$
\begin{aligned}
\max _{q D, q S} & \left\{\sum_{i}\left[\sum_{n}\left(q D_{n, i} \cdot p D_{n, i}\right)-\sum_{a}\left(q S_{a, i} \cdot c_{v a r} S_{a, i}\right)\right]\right\} \\
\text { s.t. } & q S_{a, i} \leq q S_{\text {max }_{a, i}} \\
& q D_{n, i} \leq q D_{\max _{n, i}} \\
& \sum_{a} q S_{a, i}-\sum_{n} q D_{n, i}+\sum_{i \neq j} \text { import }_{i \rightarrow j}-\sum_{i \neq j} \text { export }_{i \rightarrow j}=0 \quad \forall i \\
& \left.\sum_{i, j} \operatorname{PTDF}_{f g, i \rightarrow j} \text { export }_{i \rightarrow j}-\text { import }_{i \rightarrow j}\right) \leq F G C_{f g} \quad \forall(f g, i \neq j)
\end{aligned}
$$

with:

$f g$ : $\quad$ defined flowgate for energy trades

$P T D F_{f g, i \rightarrow j}: \quad$ PTDF for flowgate fg, energy trades from i to $\mathrm{j}(-)$

$F G C_{i \rightarrow j}$ : $\quad$ flow gate capacity between market $\mathrm{i}$ and $\mathrm{j}(\mathrm{MW})$

The load-flow-based market coupling algorithm in ATLANTIS is designed for a zonal as well as for a nodal approach and is based on an implicit auction mechanism. The power transfer distribution factors (PTDF) can be derived from the grid database in ATLANTIS. In contrast to the NTC-based market coupling in which the energy trade between adjacent bidding zones is limited by the NTC value, the maximum export/import value between neighbouring countries in the load-flow-based approach is limited by the flowgate capacity (FGC) or the capacity of defined critical branches somewhere in the network. Comparisons between NTC-based and load-flow-based market coupling are described in the literature (cf. Barth et al. 2009; Waniek et al. 2010).

The main results of the market coupling are the unit dispatch, the import/export balances of each bidding zone and the zonal prices for electricity. ${ }^{8}$ In the next model

\footnotetext{
8 The application of a nodal load-flow-based market coupling in which all network elements are modelled as critical branches would lead to the same results as a nodal pricing algorithm.
} 
step these market model results and the resulting dispatch will be evaluated in terms of a load flow calculation based on a DC load flow.

DC-optimised power flow based on market results The DC optimal power flow (DCOPF) method is based on the linear DC load flow equations (cf. Stott et al. 2009; Oeding and Oswald 2004). The AC load flow equations are shown in Eq. (3) and Eq. (4) (cf. Renner 2013, p. 43).

$$
\begin{aligned}
P_{k} & =\frac{U_{k}^{2}}{Z_{k k}} \cos \left(\psi_{k k}\right)-\frac{U_{k} U_{m}}{Z_{k m}} \cos \left(\Theta_{k}-\Theta_{m}+\psi_{k m}\right) \\
Q_{k} & =\frac{U_{k}^{2}}{Z_{k k}} \sin \left(\psi_{k k}\right)-\frac{U_{k} U_{m}}{Z_{k m}} \sin \left(\Theta_{k}-\Theta_{m}+\psi_{k m}\right) \\
\frac{1}{Z_{k k}} & =\left|\frac{1}{R_{k m}+j X_{k m}}+G_{k}+j B_{k}\right| \quad \psi_{k k}=\arg \left(Z_{k k}\right) \\
\frac{1}{Z_{k m}} & =\left|\frac{1}{R_{k m}+j X_{k m}}\right| \quad \psi_{k m}=\arg \left(Z_{k m}\right) \\
P_{k} & =Y_{k m} \cdot\left(\Theta_{k}-\Theta_{m}\right)=\frac{\Theta_{k}-\Theta_{m}}{X_{k m}}
\end{aligned}
$$

with:

$k, m: \quad$ nodes

$U_{k}$ : $\quad$ voltage at node $\mathrm{k}$ (p.u.)

$P_{k}$ : $\quad$ active power flow from $\mathrm{k}$ to $\mathrm{m}$, at node $\mathrm{k}$ (p.u.)

$Q_{k}$ : $\quad$ reactive power flow from k to $\mathrm{m}$, at node k (p.u.)

$\Theta_{k}: \quad$ voltage angle at node $\mathrm{k}(\mathrm{rad})$

$Z_{k m}$ : $\quad$ series impedance between node $\mathrm{k}$ and $\mathrm{m}$ (p.u.)

$R_{k m}$ : real part of series impedance $Z_{k m}$ (p.u.)

$X_{k m}$ : imaginary part of series impedance k and m (p.u.)

$\psi_{k m}: \quad$ angle of series impedance $Z_{k m}(\mathrm{rad})$

$G_{k}$ : real part of shunt admittance at node k (p.u.)

$B_{k}$ : imaginary part of shunt admittance at node $\mathrm{k}$ (p.u.)

$\psi_{\mathrm{km}}$ : $\quad$ angle of shunt admittance at node $\mathrm{k}(\mathrm{rad})$

In order to reduce complexity and calculation time, the $\mathrm{AC}$ power flow equations can be simplified by the following assumptions (cf. Purchala et al. 2005; Stott et al. 2009; Renner 2013):

- neglecting the terms corresponding with the active power losses in Eqs. (3) and (4) $\left(R_{k m}=0, \psi_{k m}=\pi / 2\right)$

- neglecting the shunt elements $\left(G_{k}=R_{k}=0\right)$

- assumption of small voltage angle differences leads to the approximation of $\sin \left(\Theta_{k}-\Theta_{m}\right) \approx\left(\Theta_{k}-\Theta_{m}\right)$ and $\cos \left(\Theta_{k}-\Theta_{m}\right) \approx 1$

- assumption of a flat voltage profile at all nodes $\left(U_{k}=U_{m}=1\right.$ p.u. $)$ 
The result of doing that is the linear DC load flow in Eq. (7), which focuses only on the active power flows in the network.

Overbye et al. (2004), Purchala et al. (2005), Stott et al. (2009) and Nischler (2014) have published different analysis about the usefulness of a DC load flow for power flow analysis. The conclusion is that the DC load flow can provide a good approximation of active power flows in networks in which the ratio between the series reactance $X$ and resistance $R$ is not less than 4 (cf. Purchala et al. 2005). The average error [ $P_{\text {error }}$ defined in Eq. (8)] is below $5 \%$ (cf. Fig. 3a), but errors on individual network elements can be significantly higher, with error values up to $100 \%$ (cf. Purchala et al. 2005; Stott et al. 2009). Equation (7) is also the basis for the DC-optimized power flow model in which the objective function of the common DC-OPF algorithm minimises the generation costs subject to transmission constraints (e.g. maximum transmission capacity) based on the DC load flow equation and energy balances at the nodes. For techno-economic analysis with DC-OPF models it is proposed that the value for $P_{\text {delta }}$ [defined in Eq. (9)] is below the $5 \%$ border. So it can be assured that the unit dispatch (active power injection) according the DC-OPF method is as far as possible comparable to an AC-OPF model approach. For more than 200 grid elements in a Central European control area it can be shown that $\mathrm{P}_{\text {delta }}$ for around $97 \%$ of the lines and transformers is within a band width of $5 \%$. For about $88 \%$ of grid elements the error $P_{\text {delta }}$ is not higher than $2 \%$ (cf. Fig. 3b) Nischler (2014). For the same random sample of grid elements it can be shown that high values for $P_{\text {error }}$ occur in most cases on weakly loaded grid elements (cf. Fig. 3a).

$$
P_{\text {error }}=\frac{P_{A C}-P_{D C}}{P_{A C}}
$$

with:

$P_{A C}: \quad$ active power flow according Eq. (3) (MW)

$P_{D C}: \quad$ power flow according Eq. (7) (MW)

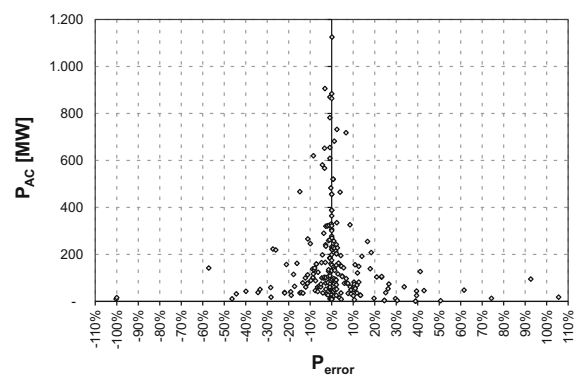

(a)

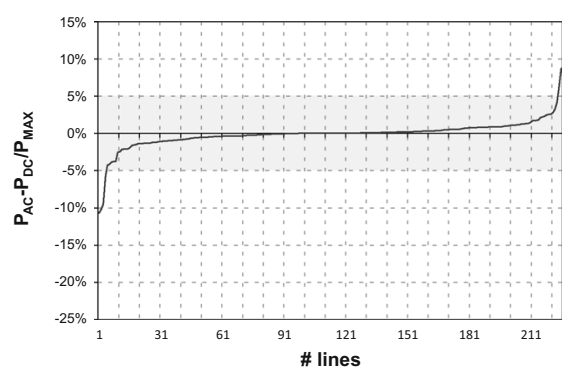

(b)

Fig. 3 Accuracy of DC load flow calculation compared to AC load flow measurements. $P_{A C}$ is based on a load flow measurement and $P_{D C}$ represents the calculated value by using the DC load flow method (cf. Nischler 2014). a $P_{\text {error }}$ for more than 200 grid elements in a Central European control area. b $P_{\text {delta }}$ for more than 200 grid elements in a Central European control area 


$$
P_{\text {delta }}=\frac{P_{A C}-P_{D C}}{P_{\max }}
$$

with:

$P_{A C}: \quad$ active power flow according Eq. (3) (MW)

$P_{D C}$ : $\quad$ power flow according Eq. (7) (MW)

$P_{\text {max }}: \quad$ maximum (thermal) transmission capacity (MW)

The DC-OPF in ATLANTIS is defined as a mixed-integer linear optimisation problem. In addition to the minimisation of generation costs the DC-OPF in ATLANTIS also optimises the use of phase-shifting transformers (cf. Nacht 2010) and HVDC links. Furthermore, the DC-OPF regards the market balance of each bidding zone (as a result of the market coupling model) to avoid a multilateral redispatch of generation units [cf. Eq. (10)]. The flowchart of the integrated DC-OPF model is illustrated in Fig. 4.

If there are congestions on transmission lines, a redispatch of generation units is carried out automatically. After this step the utilization of the power plant park is determined and the carbon dioxide $\left(\mathrm{CO}_{2}\right)$ emissions of each period can be calculated. Finally the individual profit and loss calculation of the modelled electricity companies is performed for each year.

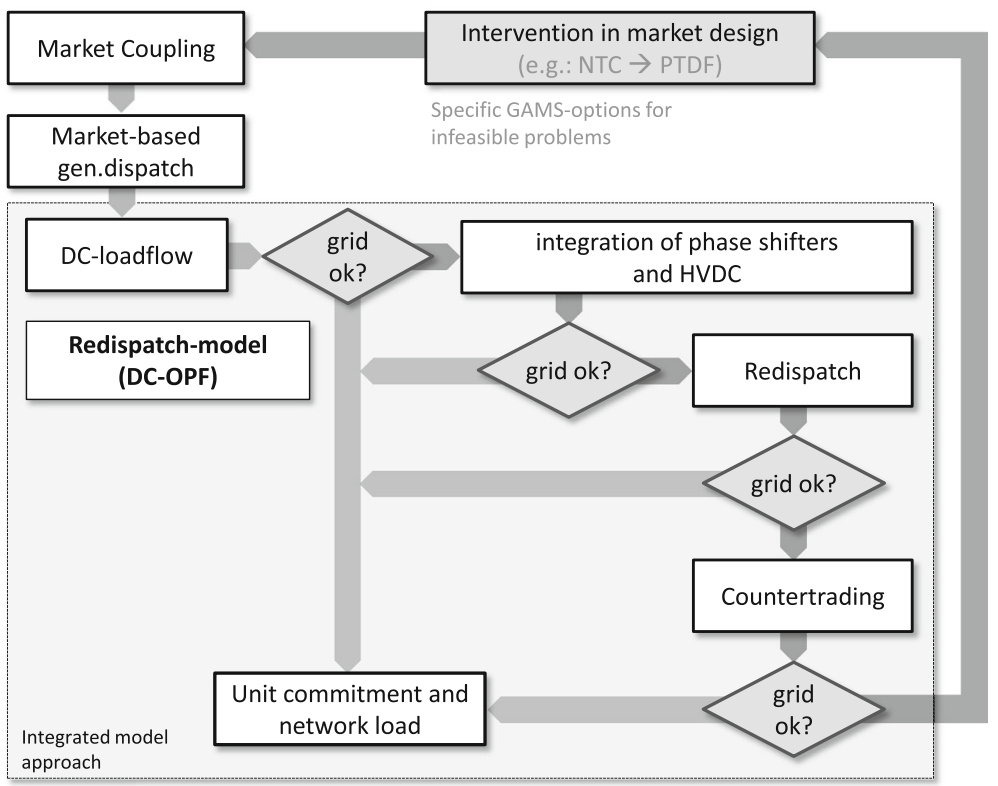

Fig. 4 Interface between market model and DC-OPF model in ATLANTIS Nischler (2014) 


$$
\begin{aligned}
& \min \left\{\sum_{G} c_{v a r, G} \cdot p_{G} \cdot P_{\text {Base }}+\sum_{l}\left(\alpha \cdot \Lambda_{l, D C}+\lambda \cdot \sigma_{l, P S T}\right)+\sum_{C} \delta \cdot H_{C}^{+}\right\} \\
& H_{C}^{+} \in\{0,1\}_{\mathbb{Z}} \\
& \text { s.t. } \sum_{G} p_{G, n}-\sum_{D} p_{D, n}=\sum_{m} \text { flow }_{n \rightarrow m}-\sum_{m} \text { flow }_{m \rightarrow n} \\
& p_{\min , G} \leq \beta \cdot p_{G} \leq p_{\max , G} \quad \beta \in\{0,1\}_{\mathbb{Z}} \\
& -p_{\text {ACmax }, l} \leq \text { flow }_{n \rightarrow m} \leq p_{\text {ACmax }, l} \quad \forall \text { AC lines } \\
& -p_{D C \max , l} \leq \text { flow }_{n \rightarrow m} \leq p_{D C \max , l} \quad \forall \text { DC links } \\
& \text { saldo }{ }_{C}^{M C}-H_{C}^{+} \cdot \Delta E X P_{C} \leq \operatorname{saldo}_{C}^{L F} \leq \operatorname{saldo}_{C}^{M C}+H_{C}^{+} \cdot \Delta E X P_{C} \\
& \sum_{G} p_{G, C}-\sum_{D} p_{D, C}-\operatorname{saldo}_{C}^{L F}=0 \\
& -\sigma_{\max , P S T} \leq \sigma_{l, P S T} \leq \sigma_{\max , P S T} \\
& -\Lambda_{\max , D C} \leq \Lambda_{l, D C} \leq \Lambda_{\max , D C}
\end{aligned}
$$

with:

$G$ :

generation units

D: $\quad$ demand

$C$ : $\quad$ market areas, bidding zones (countries)

$n, m: \quad$ nodes

$c_{\text {var }, G}: \quad$ marginal generation costs (€/MWh)

$p_{G, n}$ : (optimised) power injection of unit $\mathrm{G}$ at node $\mathrm{n}$ (p.u.)

$p_{D, n}: \quad$ demand at node $\mathrm{n}$ (p.u.)

$P_{\text {Base }}: \quad$ power base for per unit calculation (MW)

$\alpha, \delta, \lambda: \quad$ penalty weights

$\beta$ : $\quad$ binary switching variable for unit commitment $(-)$

$\sigma_{l, P S T}: \quad$ (optimised) angle of phase shifter (rad)

$\sigma_{, a x, P S T}: \quad$ maximum angle of phase shifters (rad)

flow $_{n \rightarrow m}$ : $\quad$ active power flow on line 1 between node $\mathrm{n}$ and $\mathrm{m}$ (p.u.)

$p_{\min , G}: \quad$ minimum power of unit $\mathrm{G}$ (p.u.)

$p_{\max , G}: \quad$ maximum power of unit $\mathrm{G}$ (p.u.)

$p_{A C m a x, l}: \quad$ maximum allowed transmission capacity of AC line 1 (p.u.)

$p_{D C \max , l}: \quad$ maximum power of DC line 1 (p.u.)

$\Lambda_{l, D C}: \quad$ (optimised) commitment of DC links (rad)

$\Lambda_{\text {max }, D C}$ : maximum controlling range of a DC link (rad)

$H_{C}^{+}$: $\quad$ export/import overflow in a bidding zone (binary variable) (-)

saldo ${ }_{C}^{M C}$ : $\quad$ export/import balance as result of the market coupling (p.u.)

saldo $_{C}^{L F}: \quad$ export/import balance as result of the DC-OPF (p.u.)

$\triangle E X P_{C}$ : maximum allowed countertrade (p.u.) 


\subsection{Shadow prices}

The concept of shadow prices is a useful tool in network development planning to determine optimal connection nodes for controllable HVDC systems (Nischler 2014). In economic terms, the concept of shadow prices is defined as the change in the objective cost function caused by a marginal change in the level of the affected constraint (Kallrath 2013). In this context the affected constraint is the active power flow at a node as part of a meshed grid. To realize that, first of all, in order to avoid any grid restrictions, the objective cost function [based on Eq. (11)] will be extended by an overload option $\left(\epsilon_{l}\right)$ for each line $l$. This option is weighted by a penalty $\kappa$ in avoidance of its excessive use. To highlight regional grid line bottlenecks phase-shifting transformers will not be considered $\left(\sigma_{l, P S T}=0\right)$. The first restriction of Eq. (11) will be separated into its two components- the active power flow balance as well as the generation and demand balance-in order to define the power at a node $\left(P_{n}\right)$ more generally (Nischler 2014).

$$
\begin{aligned}
& c_{\text {Total }}=\min \left\{\sum_{G} c_{\text {var }, G} * p_{G} * P_{\text {Base }}+\sum_{l} \alpha * \Lambda_{l, D C}+\sum_{C} \delta * H_{C}^{+}+\sum_{l} \kappa * \epsilon_{l}\right\} \\
& \text { s.t. }-p_{A C_{\max , l}} *\left(1+\epsilon_{l}\right) \leq \text { flow }_{n \rightarrow m} \leq p_{A C_{\text {max }, l}} *\left(1+\epsilon_{l}\right) \quad \forall \text { AC lines } \\
& P_{n}=+\sum_{m} \text { flow }_{n \rightarrow m}-\sum_{m} \text { flow }_{m \rightarrow n} \\
& P_{n}=+\sum_{G} p_{G, n}-\sum_{D} p_{D, n}
\end{aligned}
$$

with:

$P_{n}: \quad$ Power at node n (p.u.)

$\epsilon_{l}: \quad$ Overload option at line 1 (p.u.)

$\kappa: \quad$ Penalty weight for the overload option (€/p.u.)

Using the definitions from above leads to a straight forward formal derivation of the shadow prices. A shadow price $\pi_{n}$ of a node is defined as the change of total costs caused by a marginal change in the active power flow. ${ }^{9}$

$$
\pi_{n}=\frac{\partial c_{\text {Total }}}{\partial P_{n}}
$$

with:

$\pi_{n}: \quad$ Shadow price at node n (€/p.u.)

The determination of appropriate connection nodes for controllable HVDC systems depend on the level of the shadows prices as well as on the shadow price differences between the considered pairs of nodes. Nodes with negative (positive) shadow prices

\footnotetext{
9 The active power flow is defined as the sum of total outflows reduced by the sum of total inflows at a node.
} 
are characterized as electricity sources (sinks) and should be considered as feedout (feed-in) nodes for controllable HVDC lines. Finally, those pairs of nodes with the highest shadow price differences should be taken into consideration in order to minimize total generation costs (Nischler 2014). A graphical illustration of this concept as part of a visualization tool (VISU) is provided in Sect. 3.5.

\subsection{Toolbox for extreme case analysis}

In addition to the scenario analysis, which is based on average circumstances (e.g. average production of wind energy), ATLANTIS provides a toolbox for the simulation of extreme situations. It is possible to vary the power of the generation units with volatile production characteristic (e.g. wind power, hydro power, PV) for each country, the demand of each country and also the dispatch of (pumped) storage power units. Also the outage of crucial grid elements or power units can be simulated within extreme cases. With this extreme case tool it is possible to investigate the effects of extreme situations (e.g. situations with low demand, high PV generation) for example on unit dispatch, import/export balances and grid loads. Similar to a scenario simulation also the extreme case simulation is based on market coupling and DC-OPF calculations. The main results are e.g. unit (re-)dispatch, import/export balances (commercial trades and physical flows), grid loads, snap shots (cf. Fig. 9).

\subsection{Data visualisation: VISU}

The entire network development planning process is a very complex and time intensive task. As a consequence of that and in order to simplify this planning process with ATLANTIS a new visualization tool (VISU) has been developed. This tool provides a new set of opportunities to illustrate easily a set of complex simulation results. A base illustration includes a visualization of a scenario in general like a layout plan including representation of the power plants, the transmission grid system as well as regional grid nodes which represent also the distribution of the public electricity demand. Additionally more advanced illustrations including the simulation results like the DC load flow, DC load flow difference and the node based shadow prices can be created as well (Feichtinger et al. 2015).

An exemplary illustration of an ATLANTIS simulation result is provided in Fig. 5. Both illustrations consider an off-peak situation with large wind power generation in the north of Germany in 2032. The load flows (Fig. 5a) are illustrated typically using a multi-level scale whereas each level is represented by a different colour in order to visualize the different network line load flows and to clearly point out grid bottlenecks (originally plotted in dark red). Additionally, load flow differences (Fig. 5b) illustrate the effects of potential network extensions as well as power plant constructions again by using a multi-level scale with different colours.

The newly implemented concept of shadow prices enables the determination of the connection nodes for controllable HVDC systems and shows the potential effects of these network extension projects. Figure 6 demonstrates the effects of the integration of the planned HVDC systems, which will be realized in 2022. The potential effects 


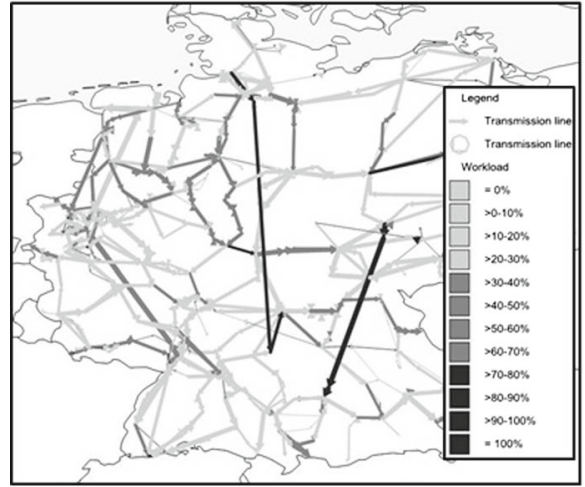

(a)

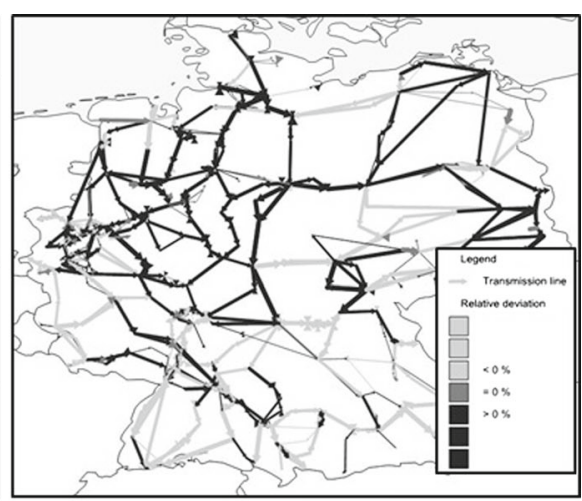

(b)

Fig. 5 Visualisation of different load flows with HVDC lines for an off-peak situation in Germany in 2032. a DC load flow. b DC load flow differences

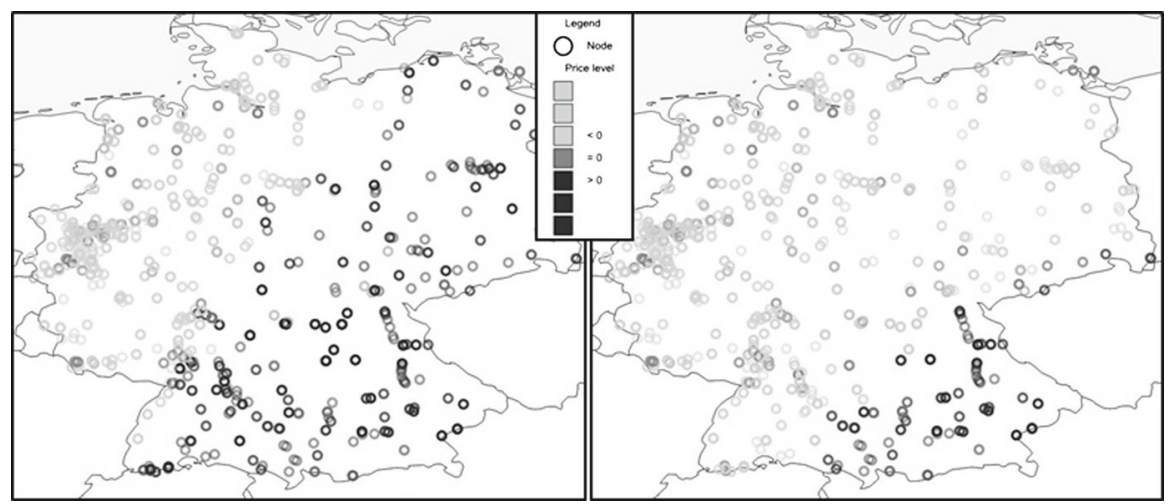

Fig. 6 (left) Shadow prices for an off-peak situation without considering HVDC systems in Germany in 2032; (right) shadow prices for an off-peak situation considering HVDC systems in Germany in 2032

10 years after the integration of the HVDC systems are huge and lead to a significant reduction in all shadow prices throughout the whole country (Fig. 6 right). Again, for the sake of a better understanding, all these illustrations consider a multi-level scale with different colours. The correct usage of these graphical illustrations can support and simplify a future-oriented network development process. Application areas are the analysis of potential effects of the realization of national or supra-national network extension projects (DC lines vs. usual AC lines vs. European Super Grid) on surrounding countries or the evaluation of single power plant projects (classical thermal power plants, renewable energies, etc.).

\subsection{Economic analysis of power utilities}

The economic part of the simulation model ATLANTIS consists of balance sheets and income statements calculated for every simulated year. At the moment there are about 


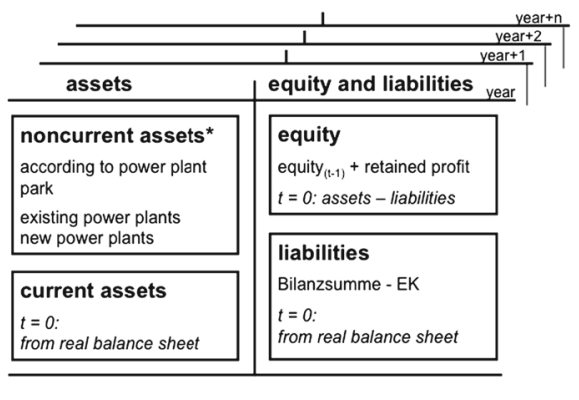

${ }^{*}$ balancing based on initial acquisition values

(a)

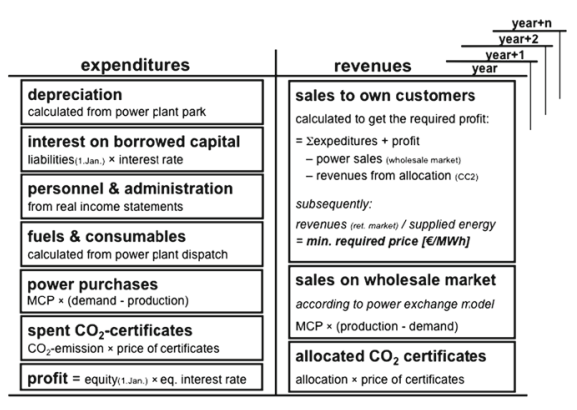

(b)

Fig. 7 Economic analysis of power utilities in ATLANTIS. a Structure of balance sheets in ATLANTIS. b Income statements in ATLANTIS

100 modelled European electricity companies included in ATLANTIS. Most of the needed values for the computation of the economic side comes from the power plant dispatch calculations. According to the scenario definition country-specific development indices are being assumed and calculated for each year. Those parameters cover e.g. primary energy indexes, personnel costs, prices for $\mathrm{CO}_{2}$ certificates and many more. Based on the yearly simulations including power plant dispatch and trade at the electricity exchange all relevant positions of the income statements and balance sheets are gained.

The structure of the balance sheets is shown in Fig. 7a. The asset side consists of non-current assets and current assets. The current assets are calculated from real balance sheets. The non-current assets are calculated on the one hand from the power plants already in operation at the beginning of the scenario simulation and on the other hand from the power plants which are newly built during the simulation period. The right-hand side of the balance consists of equities and liabilities, which are also partly calculated from real balance sheets. The income statements (cf. Fig. 7b) include all relevant positions of a real electricity company and the values are gained directly from the simulation runs. The depreciation is dependent on the age distribution of the power plants.

Capital costs are one of the main component of ATLANTIS and they are calculated within the model based on the before mentioned balance sheets and profit and loss accounts of the modelled power utilities. This allows to achieve real capital cost for the building of power plants: the depreciations of the power plants and the rate of interest for the capital employed. This approach assures that the modell uses the real capital cost which are different from the macroeconomic capital cost. ATLANTIS calculates the depretiations from the historic acquisition values and the rates of interest based on the needed capital. The needed capital is calculated from the historic acquisition values reduced by the sum of the depreciations. This approach allows under consideration of the inflation and the age structure to calculate the needed real business economical capital cost for the existing as well as the new scenario-power plants. Therefore ATLANTIS enables to describe the effects of different market designs with regard to the companies of the electricity economy. 


\section{Examples for the application of ATLANTIS}

This chapter describes some applications of the simulation model ATLANTIS. Since the complete simulation model ATLANTIS and the database is an in-house development it can be adapted to different research questions. The following examples give an overview of the broad application possibilities of ATLANTIS using the examples of already finished research projects.

\subsection{Network development in Austria}

In 2009 the Austrian TSO Austrian Power Grid (APG) published a master plan regarding the network development until 2020. Due to drastic changes in the European electricity economy, like the phasing out of nuclear production e.g. in Germany and Switzerland and the installation of more RES power plants like PV and wind power, this plan had to be adapted and the new master plan 2030 was formulated end published in 2012 (cf. APG 2013). Although it is an Austrian network development plan it is important to consider also the surrounding European electricity system and therefore the simulations have been done using ATLANTIS.

Prior to the simulations the worldwide framework conditions as well as the European development goals and legal guidelines were investigated. Based on those outcomes different scenarios have been defined and the market as well as load flow simulations have been done for a base case. Each simulated month has been divided into four load cases (peak, peak with high usage of pumped-storage power plants, offpeak, off-peak with high usage of pumped-storage power plants), which leads to 48 yearly load flow calculations. At the beginning of each year the coverage of the peak load has been checked for the winter and summer period. Consequently there have to be calculated yearly 50 load flows, which amounts to 1000 load flow calculations within the period 2011-2030. In addition, selected extreme cases have been calculated for the years 2015, 2020, 2025 and 2030. As an example Fig. 8 shows the DC laod flow result for a "cold winter" case with low hydro power generation in the alpine region, low wind generation in Northern Europe and a peak load demand in Austria. The simulations show that future network congestions could occur on selected $220 \mathrm{kV}$ lines and that the new/planned $380 \mathrm{kV}$ overhead lines "Steiermarkleitung" and "Salzburgleitung" could improve the situation significantly. Detailed information about this project can be found in Reich et al. (2012).

\subsection{Network development plan of Germany}

The German electricity system was originally characterized by power plants with a high installed capacity located near the demand. Due to the changing characteristics especially of the German electricity system because of the phase out of the nuclear power plants, and the widespread installation of wind and PV power plants the function of the electricity grid changes from interconnection-orientation to a transmissionorientation. 


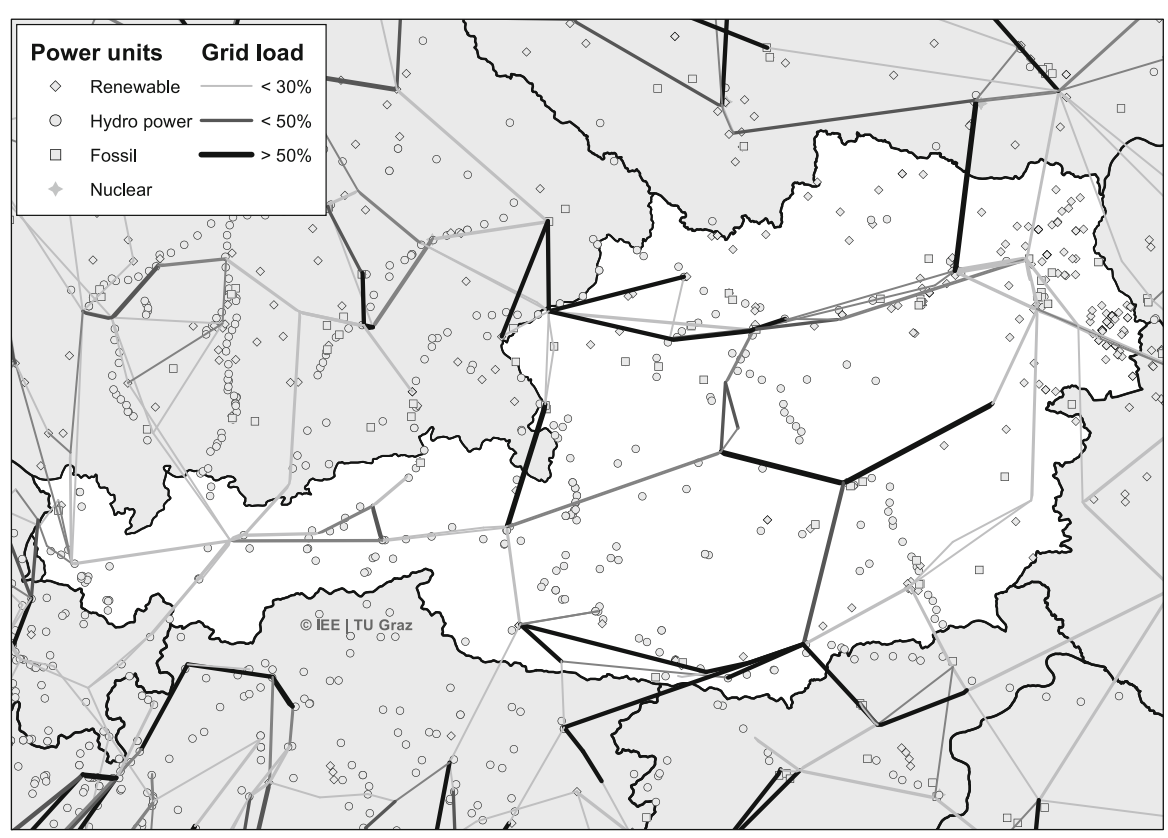

Fig. 8 DC load flow result for a "cold winter" case with low hydro power generation in alpine regions, low wind generation in Northern Europe and a peak load situation in Austria
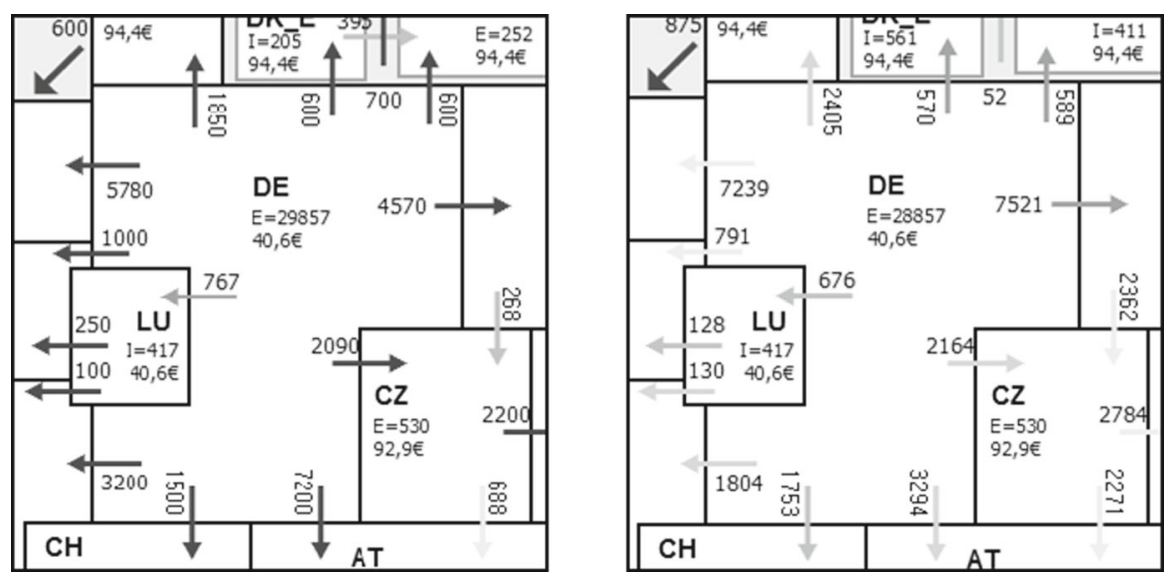

Fig. 9 Snapshots from ATLANTIS for an extreme case with peak load demand, high wind production and low PV generation in 2032. Commercial cross-border flows (left) and physical cross-border load flows (right) (cf. Stigler et al. 2012)

Due to those developments also the future network development has to be adapted. ATLANTIS has been used for simulation calculations by order of the German regulation authority "Bundesnetzagentur". Within this project the following points have been investigated: 
- Analysis of weaknesses of the German transmission network based on three given scenarios and selected network usage cases

- Analysis of the effect and benefit of controllable bulk power transmission lines (e.g. HVDC links) on the electricity system

- Determination of the needed network developments under certain conditions

As an example Fig. 9 shows the commercial cross-border flows according to the NTC-based market coupling model (left) and the physical cross-border load flows according to the DC-OPF model (right) for an extreme situation with peak load demand, high wind production and low PV generation in Germany for the year 2032. A comprehensive description of the approach and results can be found in Stigler et al. (2012).

\subsection{Analysis of the impact of the climate change on the electricity sector}

Electricity production not only contributes to the greenhouse gas emissions but is also vulnerable to changing climatic conditions, especially due to the rising amount of electricity generation from RES. In the long run, temperature changes also lead to a change on the electricity demand side. Electricity is an important and relevant input factor for many other economic branches and therefore changes in the e.g. power plant structure also influence the rest of the economy. Some works focus on questions regarding future investments under certain regulatory conditions (cf. Nagel and Rammerstorfer 2009; Klingelhöfer and Kurz 2011) but the aim of the project El.Adapt was to develop an integrated modelling framework to describe and analyse the requirement for and economic consequences of adaptations in the electricity sector in Austria on a time scale up to 2050. Due to the cross-cutting nature of the problem, an integration (or coupling) of different models has been done. For the analysis of the consequences of the climate change on the electricity sector, high-resolution climate change scenarios have been used as input to the hydrological model in order to determine changes in hydrology. Those changes are relevant for the hydropower generation, which is an input to the electricity sector models (temporal and spatial high resolution temperature, precipitation, river discharge, and wind data). Because of the interdisciplinary nature of the problem, the techno-economic electricity sector model (ATLANTIS) has been coupled with a multi-country multi-sector computable general equilibrium (CGE) model (based on GTAP ${ }^{10} \mathrm{v} 7$ ). A precise description of the modelling aproach and of the results can be found in Stigler et al. (2013).

\subsection{E-mobility}

Emission reductions and an increase in energy efficiency are the key benefits of e-mobility. As for energy consumption, the manufacturers information shows the superiority of e-cars in comparison to conventional cars. In analogy to conventional cars, the consumption in practical application will be higher than the theoretical values. The

10 Global Trade Analysis Project. 
potential for emission reduction is high, especially if the potential of RES in Austria is used. Even if the electricity would be produced by fossil fuels, e-cars show emission reduction potential in comparison to conventional cars. Even in the case of high market shares of e-cars, e-mobility does not lead to much additional energy consumption. By the use of load control methods the existing distribution grid will be widely sufficient. Although the development of charging infrastructures is one of the key challenges, the development of cost-effective and suitable batteries should not forgotten (cf. Zoglauer et al. 2010). In the project "e-mobility 1.0" a model for the evaluation of the additional power needs due to e-mobility has been combined with ATLANTIS in order to investigate the effects on the electricity system. A detailed description of the used models and the results can be found in Huber et al. (2012).

\section{Conclusions and outlook}

The global energy economy faces huge challenges. Population growth with an ongoing increasing energy demand, the situation of fossil fuels in terms of still high usage, price distortions and geographical distribution of the reserves as well as the environmental impacts like the accident in Fukushima and the ongoing climate change lead to a rethinking of the energy system. Especially due to the high import dependency of Europe on fossil fuels, Europe decided to establish a challenging energy strategy e.g. in terms of increasing the usage of RES.

Within the whole energy sector the electricity sector plays an important role, because it is of superior significance for the functioning of the whole economy and society. In contrast to other sectors, this sector is characterized by particularities like non-storable production, necessity of a network, very high capital intensity and long lifetimes of the facilities. Moreover it is a complex technical as well as economic system, which can only be regarded in one piece. The framework conditionsstated at the beginning also hold true for the European electricity sector and the last years are especially characterised by a massive increase in RES production facilities-especially in Germany - and plans for shutting down of numerous nuclear power plants. Those developments lead to the situation that the existing electricity market is not reacting properly and needs to be redesigned.

In order to analyse different paths for the future development of the European electricity sector it is meaningful to do simulation-based investigations in order to find out the effects of new measures and changes in the framework conditions/regulations. To do such investigations corresponding models are needed. There are several different model approaches and this paper describes the simulation model ATLANTIS. ATLANTIS has been developed at the Institute of Electricity Economics and Energy Innovation and is an interdisciplinary, techno-economic simulation model of the European electricity sector and considers the complex relations within this important sector. It allows scenario-based investigations of future developments up to the year 2050. This paper describes the structure and single parts of the model in detail. So far the model has been used for the investigation of different scientific questions and four example applications are described in the paper. The applications of ATLANTIS cover scenario calculations for network development plans in different European countries, 
investigations regarding the role of greenhouse gas emissions in the electricity sector and even analyses the effects of e-mobility strategies on the electricity system.

ATLANTIS is in ongoing development and further improvements and possible applications cover e.g. following fields:

- System integration of RES: phasing in of RES/phasing out of conventional power plants in Europe and specific regions

- Network development planning: new planning approaches (cf. Stigler et al. 2015) as well as new supporting tools (cf. Feichtinger et al. 2015)

- Development of the conventional power plant park: localization and determination of the needed conventional power plant capacity

- European electricity market: design principles and options for the future market like strategic reserve or direct marketing of RES (cf. Stigler and Bachhiesl 2015)

- Effect of different regulatory measures: energy efficiency policies, different promotion schemes for RES, emission trading mechanisms

Acknowledgments The simulation model ATLANTIS has been developed at the Institute of Electricity Economics and Energy Innovation at Graz University of Technology. In order to establish the model and to build up the unique database many persons have contributed in terms of scientific works. The historic roots of the model as well as the main contributions are described at the homepage of the institute (www. IEE.TUGraz.at).

Open Access This article is distributed under the terms of the Creative Commons Attribution 4.0 International License (http://creativecommons.org/licenses/by/4.0/), which permits unrestricted use, distribution, and reproduction in any medium, provided you give appropriate credit to the original author(s) and the source, provide a link to the Creative Commons license, and indicate if changes were made.

\section{References}

APG (2013) Masterplan 2030-Für die Entwicklung des Übertragungsnetzes in Österreich Planungszeitraum 2013 bis 2030. Mit Ausblick bis 2050. APG: Austrian Power Grid. http://www.apg.at

Barth R, Apfelbeck J, Vogel P, Meibom P, Weber C (2009) Load-flow based market coupling with large-scale wind power in Europe. In: 8th international workshop on large-scale integration of wind power into power systems as well as on transmission networks for offshore wind farms. Energynautics $\mathrm{GmbH}$, pp 296-303

Bundesnetzagentur (2015) List of power plant closure notifications. http://www.bundesnetzagentur.de

BWE (2014) Installed wind power capacity in Germany. German Wind Energy Association. http://www. wind-energie.de

Capros P (2000) The primes energy system model: summary description. http://www.e3mlab.ntua.gr

CASCEU (2013) Documentation of the CWE FB MC solution: as basis for the formal approval-request. CASC. http://www.casc.eu/en/Resource-center/CWE-Flow-Based-MC/Approval-Documents. Accessed 102013

Doquet M, Gonzalez R, Lepy S, Momot E, Verrier F (2008) A new tool for adequay reporting of electric systems: ANTARES. In: CIGRE 2008 session, paper C1-305, Paris

Doquet M, Fourment C, Roudergues J (2011) Generation amp; transmission adequacy of large interconnected power systems: a contribution to the renewal of Monte-Carlo approaches. In: PowerTech, 2011 IEEE Trondheim, pp 1-6. doi:10.1109/PTC.2011.6019444

ENTSO-E (2012) Network code on capacity allocation and congestion management (cacm). Website ENTSO-E. http://www.casc.eu/en/Resource-center/CWE-Flow-Based-MC/Approval-Documents. Accessed 102013

ETSO (2001) Procedures for cross-border transmission capacity assessments. Website ENTSO-E. https:// www.entsoe.eu/fileadmin/user_upload/_library/ntc/entsoe_proceduresCapacityAssessments.pdf. Accessed 102013 
EWI Cologne (2014) Description of models MORE and DIMENSION. http://www.ewi.uni-koeln.de

Feichtinger G, Nischler G, Stigler H, Bachhiesl U (2015) Neue Instrumente zur visuellen Unterstützung der Netzentwicklungsplanung mittels ATLANTIS. 9. Internationale Energiewirtschaftstagung, TU Wien

Fichtner W (1999) Strategische Optionen der Energieversorger zur $\mathrm{CO}_{2}$ Minderung: ein Energie-und Stoffflussmodell zur Entscheidungsunterstützung. Erich Schmidt, Berlin

Genoese M, Sensfuß F, Möst D, Rentz O (2007) Agent-based analysis of the impact of $\mathrm{CO}_{2}$ emission trading on spot market prices for electricity in Germany. Pac J Optim 3:401-423

Genoese M, Möst D, Fichtner W (2008) Agentenbasierte Simulation zur Messung von Marktmacht Eine Analyse fur den deutschen Strommarkt. In: Workshop Energiesystemanalyse, KIT Zentrum Energie

Huber C, Hütter D, Schüppel A, Tyma F, Gutschi C, Beermann M, Felberbauer K, Canella L (2012) e-Mobility 1.0: challenges of the large-scale introduction of battery-powered electric vehicles in Austria. http://www.klimafonds.gv.at

Kakogiannis N, Kontogiorgos P, Sarri E, Papavassilopoulos G (2014) Multicriteria energy policy investments and energy market clearance via integer programming. Cent Eur J Oper Res. doi:10.1007/ s10100-014-0351-X

Kallrath J (2013) Gemischt-ganzzahlige optimierung: modellierung in der praxis. Springer, Wiesbaden. doi:10.1007/978-3-658-00690-7

Klingelhöfer HE, Kurz P (2011) Financial valuation of investments in future power generation technologies: nuclear fusion and ccs in an emissions trading system. Cent Eur J Oper Res 19(4):415-438. doi:10. 1007/s10100-011-0193-8

Kocan M (2008) Cyclic behavior in dynamic investment decisions for deregulated energy markets. Cent Eur J Oper Res 16(1):67-78. doi:10.1007/s10100-007-0043-x

Kurzidem M (2010) Analysis of flow-based market coupling in oligopolistic power markets. Ph.D. thesis, ETH Zurich

Leuthold F, Weigt H, Hirschhausen C (2010) A large-scale spatial optimization model of the European electricity market. J Netw Spat Econ 12(1):75-107. doi:10.1007/s11067-010-9148-1

Loulou R, Remne U, Kanudia A, Lehtila A, Goldstein G (2005) Documentation for the times model. http:// www.iea-etsap.org

Louyrette J, Trotignon M (2009) European market couplings: description, modelling and perspectives. In: PowerTech, 2009 IEEE Bucharest. doi:10.1109/PTC.2009.5282203

Maier K (2010) Analyse des iberischen Elektrizitätssystems unter besonderer Berücksichtigung der erneuerbaren Energien. Master's thesis, TU Graz

Mayer C (2010) Potenziale erneuerbarer Stromerzeugung in Italien und Frankreich. Master's thesis, Graz University of Technology

Möst D (2006) Zur Wettbewerbsfähigkeit der Wasserkraft in liberalisierten Elektrizitaätsmaärkten: eine modellgestutzte Analyse dargestellt am Beispiel des schweizerischen Energieversorgungssystems. PhD thesis, University of Karlsruhe

Nacht T (2010) Lastflussbasierte Optimierungsalgorithmen in der Elektrizitätswirtschaft. Master's thesis, Graz University of Technology

Nagel T, Rammerstorfer M (2009) Modeling investment behavior under price cap regulation. Cent Eur J Oper Res 17(2):111-129. doi:10.1007/s10100-008-0078-7

Nischler G (2009) Engpassmanagement auf grenzüberschreitenden Leitungen: Aktuelle Entwicklungen und Modellierungsansätze. Master's thesis, Graz University of Technology

Nischler G (2014) Zukunftsorientierte elektrizitätswirtschaftliche Netzentwicklung. PhD thesis, dissertation, Graz University of Technology

Oeding D, Oswald BR (2004) Elektrische Kraftwerke Und Netze. Springer. http://books.google.at/books? id=9whdPFtlqxIC

Overbye T, Cheng X, Sun Y (2004) A comparison of the ac and dc power flow models for lmp calculations. In: Proceedings of the 37th annual Hawaii international conference on system sciences, 2004. p 9. doi:10.1109/HICSS.2004.1265164

Purchala K, Meeus L, Van Dommelen D, Belmans R (2005) Usefulness of dc power flow for active power flow analysis. In: power engineering society general meeting, 2005, vol 1. IEEE, pp 454-459. doi:10. 1109/PES.2005.1489581

Regos G (2013) Comparison of power plants risks with multi criteria decision models. Cent Eur J Oper Res 21(4):845-865. doi:10.1007/s10100-012-0257-4

Reich K, Gutschi C, Nischler G, Nacht T, Stigler H (2012) Szenarienanalysen für den Masterplan 2030 der Austrian Power Grid AG. 12. Symposium Energieinnovation, TU Graz 
Remme U (2006) Zukünftige Rolle erneuerbarer Energien in Deutschland: Sensitivitätsanalysen mit einem linearen Optimierungsmodell. Ph.D. thesis, University of Stuttgart

Renner (2013) Regelung und Stabilität elektrischer Energiesysteme. IFEA, TU Graz

Schüppel A (2010) Modellierungsansätze zur Beschreibung dargebotsabhängiger Stromerzeugung. Master's thesis, Graz University of Technology

Stigler S, Feichtinger G, Bednar-Friedl B, Gobiet P (2013) Impacts of climate change and adaptation in the electricity sector the case of Austria in a continental European context. https://wegcenter.uni-graz.at/ de/forschen/forschungsgruppe-reloclim/projekte/abgeschlossene-projekte/eladapt/

Stigler H (2002) Die Anforderung an die Energieinnovation II. In: Symposium Energieinnovation

Stigler H, Bachhiesl U (2014) Zur Anwendbarkeit von NTC, PTDF, Energy-Only-Markt, Nodal Pricing Modelle und Implikationen. In: 13. Symposium Energieinnovation: Innehalten und Ausblick: Effektiviät und Effizienz für die Energiewende

Stigler H, Bachhiesl U (2015) Zur ökonomischen Fundierung des Energy-only Marktes. 9. Internationale Energiewirtschaftstagung, TU Wien

Stigler H, Nischler G, Renner H, Fickert L, Brandauer W, Bachhiesl U et al (2012) Gutachten zur Ermittlung des erforderlichen Netzausbaus im deutschen Übertragungsnetz 2012. http://data.netzausbau.de/Alfa/ NEP/NEMO_II.pdf

Stigler H, Nischler G, Feichtinger G, Bachhiesl U (2015) Zukunftsorientierte elektrizitätswirtschaftlich fundierte Netzentwicklungsplanung. 9. Internationale Energiewirtschaftstagung, TU Wien

Stott B, Jardim J, Alsac O (2009) DC power flow revisited. IEEE Trans Power Syst 24(3):1290-1300. doi:10.1109/TPWRS.2009.2021235

Thery R, Zarate P (2009) Energy planning: a multi-level and multicriteria decision making structure proposal. Cent Eur J Oper Res 17(3):265-274. doi:10.1007/s10100-009-0091-5

Vasin A, Kartunova P, Weber GW (2013) Models for capacity and electricity market design. Cent Eur J Oper Res 21(3):651-661. doi:10.1007/s10100-012-0259-2

Vespucci MT, Bertocchi M, Innorta M, Zigrino S (2014) A stochastic model for investments in different technologies for electricity production in the long period. Cent Eur J Oper Res 22(2):407-426. doi:10. 1007/s10100-013-0317-4

Waniek D, Rehtanz C, Handschin E (2010) Flow-based evaluation of congestions in the electric power transmission system. In: Energy market (EEM), 2010 7th international conference on the European, pp 1-6. doi:10.1109/EEM.2010.5558762

Wirth H (2015) Aktuelle Fakten zur Photovoltaik in Deutschland. Website Fraunhofer-Institut fur Solare Energiesysteme ISE. http://www.pv-fakten.de

Zoglauer M, Nischler G, Gutschi C, Süssenbacher W, Otzasek S, Stigler H (2010) Auswirkungen zukünftiger Elektromobilität auf die österreichische Elektrizitätswirtschaft. In: 11th Symposium energy innovation, Verlag der TU Graz. http://www.EnInnov.TUGraz.at 